\title{
From Longhand Writing to Word Processing: A Phenomenological Study of the Technophobe Turned Novelist
}

\author{
Antonio Díaz Andrade \\ Auckland University of Technology, Auckland, New Zealand \\ antonio.diaz@aut.ac.nz
}

\begin{abstract}
Firmly grounded on the assumption that using digital technology is an intentional, conscious and subjective experience, this study adopts a transcendental phenomenological approach to reveal the meaning of the individual experience of using digital technology. This study reports the experience of a self-described technophobe, creative woman, who, after learning how to type on a computer keyboard, used word processor software on a donated computer to write and eventually publish a novel. As result of a reflective analysis, according to the tenets of transcendental phenomenology, the essence of the lifeworld phenomenon of using digital technology revealed three interdependent experiences: imaginative, epiphanic and symbiotic. This study explains how an individual uses digital technology to fulfil her needs and achieve her goals as well as demonstrates the potential of transcendental phenomenology in information systems research.
\end{abstract}

Keywords: essence, experience, technophobe, transcendental phenomenology

\section{Introduction}

The ability to use digital technology can have major repercussions on the pursuit of personal goals. Indeed, digital technology can serve as a vehicle to unravel talents that otherwise would remain unrealised and ultimately contribute to fulfilment of the individual.

Unlike previous information and communication technology for development studies that investigate the collective dimension - e.g., data standardisation in healthcare systems [1], technological platforms for poverty alleviation [2], integration of scientific and indigenous knowledge [3], institutional contexts in the implementation of information systems [4] - this paper emphasises the individual experience. In this study, I present the analysis of the journey experienced by an extraordinarily creative woman from outright refusal of using digital technology to embracing the use of word processor software. The fact that she still admits a high degree of fear when using digital technology, regardless of the benefits she derives from word processor software, characterises her as a technophobe.

The use of digital technology by a technophobe to achieve her goals and fulfil her needs constitutes an exceptional phenomenon. In order to understand the essence of her

adfa, p. 1, 2011.

(C) Springer-Verlag Berlin Heidelberg 2011 
technophobic experience in relation to digital technology use, I give primacy to her lifeworld as experienced and described by her. Therefore, I adopt a transcendental phenomenological approach to address the following research question:

What is the experience of a technophobe when using digital technology?

This paper is organised as follows. The next section provides the theoretical background of lifeworld experience in relation to digital technology use. The third section explains the research methods. The fourth section introduces the research participant. The fifth section presents the synthesis of my research participant's experience in relation to digital technology use. The last section presents the conclusions of the paper.

\section{The Experience of Using Digital Technology}

In this section, I discuss conscious actions in relation to digital technology use and present an outline of previous research on technophobia.

\subsection{Conscious use of digital technology}

Using digital technology is a conscious act. In their engagement with technology, individuals are not merely passive subjects with no sense of purpose. Labelling individuals who use technologies merely as 'users' is a misnomer. The term 'users' evokes an homogenising and rather inaccurate description of what in reality constitutes a collection of diverse individuals with unique interests in a particular context that characterises their encounter with technology. Digital technology is an inviting and interpretively flexible artefact that offers a dense and variable set of functionalities to individuals [5].

Individuals exercise judgment through critical consciousness in order to assess how and to what extent digital technology can help them address their needs and achieve their goals [6,7]. Furthermore, the assessment of the usefulness of technology for attaining specific aims is influenced by their personal histories and circumstances [8]. Individuals use digital technology for multiple purposes: to access information, to produce content, to connect with others and to participate in social life. Consequently, what individuals make of a particular technology is a complex accomplishment involving human intentions, the properties of technology and the specific environment in which they are located [9]. Although recognising the malleable properties of digital technology allows a fine-grained analysis of the interlock between individual actions and technology performance [10], it does not reveal how emotions emerge in this interaction.

Understanding emotions when individuals engage in digital technology use in an everyday situation requires recognising the indivisibility of individuals' histories and their efforts to make sense of technology in their pursuit of goals and fulfilment of needs. Emotions can be intimate and somewhat unfathomable, but "they precede or, better, ground any mental representation of the situation and action strategy ... they are not the direct consequence of our thinking, doing, and acting. Instead, they are the presupposition, the medium within which those activities take place" [11, pp. 32-33]. The mechanisms that explain how individuals use - or avoid using - digital technology are "are to be found in the intersubjective, intentional actions of human beings, not some 
mythological rational calculus that stands us as general law" [12, p. 198]. This is particularly true in the case of individuals who fear using digital technology.

\subsection{Technophobic feelings and using digital technology}

With the popularisation of personal computers in the early 1980s also came the fear of using them. The term computerphobia described the anxiety generated by using computers, the concerns about the societal implications of computer technology and/or "specific negative cognitions ... during present computer interaction or when contemplating future computer interaction" [13, p. 362]. Grounded on the observation that individuals avoid engaging in activities that they believe they will not be able to cope with - cf. Bandura's [14] notion of self-efficacy, research corroborated that low perceptions of self-efficacy in computer use makes the individual believe not only that the outcome will be negative but also will reinforce their fear about computers [15].

The term computerphobia was abandoned in favour of a more comprehensive one, technophobia. A perverse circle between internally-generated anxiety about using technology and the reluctance of using it "maintains the technophobe's belief system as the technophobe never comfortably interacts with technology and thereby challenges or changes these beliefs" [16, p. 28]. The lack of experience in the first encounter with digital technology generates anxiety that persists in future encounters [17]. However, a distinction needs to be made between using digital technology and the task that it facilitates. Digital technology is the tool that mediates the accomplishment of a task. This distinction is illustrated in Brosnan's [18] study, who observes that the action of writing does not produce anxiety; the use of word processor software does. Unravelling the feelings of fear and anxiety that technophobes experience in their engagement with technology requires bringing to the foreground the messiness of the managing-in-thenow that characterises digital technology use. These fears and anxieties can only be understood and explained by the individual who experiences using digital technology.

\section{Research Methods}

Understanding the essence of the experience of what really is using technology for a technophobe requires privileging the standpoint of the person who lives the experience. By rejecting the dichotomous conceptualisations of subject/object, mind/body and cognition/action [19], phenomenology focusses on consciousness and subjectivity to derive knowledge about the intimate experience of using technology [12]. In general, phenomenology is a "method of scientific philosophy [that] tries to discover the essences of appearances which are anything which human beings can become conscious" [20, p. 53]. Rooted on how individuals construct meanings and values, phenomenology is a critical reflection on conscious experience designed to uncover the essential invariant features of that experience [21]. Therefore, the task of phenomenology is to understand "the way in which consciousness gives meaning" [22, p. 10].

Transcendental phenomenology is the thick description of "what one perceives, senses, and knows in one's immediate awareness and experience... [that] provides the 
impetus for experience and generating new knowledge" [23, p. 26]. Two key elements of Husserl's thinking are reflected as central tenets of transcendental phenomenology. The first one is the understanding that consciousness is intentional: it "is always 'consciousness' of something; it always 'intends' something, or is 'about' something" [24, p. 1236]. The second one is that objective reality only exists in mental representations; therefore, the former is nothing else than subjective reality [23].

\subsection{Data Collection}

I sought for individuals whose use of digital technology had a substantial repercussion in their lives. I directed my search to beneficiaries of the Computers in Homes programme, a New Zealand government-funded initiative that provides basic computer training to parents with school-aged children of low socio-economic background. Upon satisfactory completion of the computer-training course, participants receive a refurbished desktop computer with free broadband connection for one year. I was put in contact with Sarah, ${ }^{1}$ a 56-year-old solo mother of a teenage daughter. As a self-confessed "technophobe" that learned how to use word processor software to write her novels, Sarah's experience is particularly interesting for this phenomenological study.

Data were collected through a series of three face-to-to-face, in-depth, unstructured interviews. In line with the tenets of phenomenological research, I refer to Sarah not as my research participant but as my co-researcher. Although I had developed a series of questions aimed at prompting Sarah to share with me her overall experience with digital technology, they were used as a guide only. In my interaction with her, I endeavoured to capture faithfully the essence of the phenomenon while suspending any pre-conceived judgement [22]. The interviews flowed as natural conversations; I actively listened to her experiences and followed her leads with probing questions whenever it was necessary. Her talkative character and well-articulated reflections about the phenomenon under study facilitated my access to her lived experiences.

The three interviews, conducted over a period of two weeks between June and July 2016, took place in a meeting room at the local library of Waitopu Island, ${ }^{2}$ where Sarah lives. With her consent, we produced 3 hours and 20 minutes of audio recordings, which were later uploaded into NVivo software package. However, our interaction went beyond the audio-recorded interviews. When I met Sarah for the first time, Sarah gave me a 10-minute tour around the public library before we went into the meeting room for the 1-hour-and-10-minute audio-recorded interview. Following this conversation, we continued the talk for another hour at a local café and then strolled together for ten more minutes. The second audio-recorded interview took place one week later and lasted for over one and half hours; the third one went for 40 minutes. As in the first interview, for the subsequent ones we also had short conversations before and after the interviews. These conversations, which were not audio-recorded, contributed to establish a trusting atmosphere between Sarah and me. Overall, our face-to-face interaction extended for over five hours and we continue the communication via email.

\footnotetext{
${ }^{1}$ Sarah is a pseudonym.

${ }^{2}$ The name of this island is fictitious.
} 


\subsection{Data Analysis}

Given its focus on the phenomenon as lived by the individual [25], transcendental phenomenological analysis proceeds by describing the essence of a lived experience, which represents the true nature of the phenomenon being studied [26]. As such, the results of phenomenological enquiry should be a thick and direct description of the lived experience [27]. Adopting a transcendental phenomenology approach required making Sarah the focal actor in the analysis. Thus, in this study, I focussed my attention on her involvement with digital technology and its meaning for her.

Doing transcendental phenomenological research requires intuitive thinking to derive knowledge "from first-person reports of life experiences" [23, p. 84]. In doing so, when I analysed Sarah's inward experiences of her use of digital technology, I followed four analytical processes in order to discover the essence of the phenomenon: epoqué, transcendental-phenomenological reduction, imaginative variation and synthesis.

Practicing the epoque involves bracketing and putting aside pre-conceived ideas to have a fresh look at the phenomenon under study [23]. Epoqué started early in the research process, when I interacted with Sarah for the first time and before each subsequent interview. At this stage, I endeavoured to be receptive to what just Sarah was saying, making a conscious effort to avoid having my intuitive thinking clouded with my own preconceptions. I primed myself to observe and learn about the phenomenon as it appeared and nothing else. In my first encounter with the audio-recorded data, I practised the procedure of "horizonalising the data" [23, p. 118], by which every one of Sarah's statements relevant to the research question were granted equal value.

Transcendental-phenomenological reduction entails deriving a "textural description of the meanings and essences of the phenomenon, the constituents that comprise the experience in consciousness" [23, p. 34]. I was looking at the elements of Sarah's experience that appeared in front of me in order to produce a list of meaning units. I relied on NVivo for recording these meaning units through a taxonomy exercise that involved an iterative process of looking at the data to notice something and reflectively looking again to get an understanding of the phenomenon in its totality. The horizonalising process continued during the transcendental-phenomenological reduction since "a new horizon arises each time that one recedes" [23, p. 95].

Having already identified the meaning units, I embarked on the imaginative variation to produce a portrayal of the essences of the experience. Imaginative variation demands assuming that "existence no longer is central, anything whatever becomes possible. The thrust is away from facts and measurable entities and toward meanings and essences" [23, p. 98]. I implemented the imaginative variation by debating with myself, until I got a sense of conceptual closure, for alternative explanations of what invariant structures triggered Sarah's feelings and thoughts in her interaction with digital technology. Eventually, by clustering the meaning units I had previously identified under three essences that that provide a structural description of the phenomenon.

Finally, for the synthesis, I integrated the meanings and essences. I am cognizant that the account I render of Sarah's lived experience in relation to digital technology reflects the thick description of the phenomenon, circumscribed by my reflective and intuitive analysis conducted at a particular time and space. 


\section{Introducing Sarah}

Sarah loves the "sense of island community", although laments that Waitopu Island is no longer what used to be. She broadly describes the socioeconomic composition of the island as one of two extremes: "you have the extremely wealthy, multimillionaires ... and then you have the rest of the population". She proudly declares that she belongs to the latter group. Waitopu Island was traditionally the home of retirees, beneficiaries and alternative people; not anymore. She remembers the days on which whenever a helicopter flew over the island, it was the police searching for weed plantations; nowadays, hovering helicopters are manned by the affluent locals or flying rich tourists.

Her three-month stay in Nowhere Island, ${ }^{3}$ after completing her first year of university studies in the late 1970s, reinforced her liking for the sense of island community. Initially, Sarah was hesitant to take a waitressing role there because she was just 17 and "quite reserved" but eventually accepted the challenge. After this period, she returned to New Zealand to continue her university studies. Then, she decided to go back to Nowhere Island, but this time to work as a painter full-time and to do dishwashing on a part-time basis for one year. During this period, she painted intensely and learned to be an independent person. Once back in New Zealand, she completed her Bachelor of Arts in Art History in 1980. Upon graduation, she worked for two years "just drilling holes in circuit boards" only because she had a mortgage to pay for the house she bought in Waitopu Island in 1980. In 1984, she got a job as a receptionist in a physiotherapy clinic, where she worked for 12 years until the final stages of her pregnancy. In 1997, she suffered a serious accident when an elder driver blacked out: "he literally ran over top of me, I was caught up under the wheels and sprang out and somersaulted into the path of incoming traffic. It was really bad". After recovery, Sarah worked at a toy store for the next few years and, for the last six years, as a cleaner. She never enjoyed the jobs that she has done but conceded that they gave her time to do the activities that she really was passionate about: painting, sculpting and, during the last few years, writing.

\section{$5 \quad$ Findings}

In the following sub-sections, I present the synthesis of Sarah's experiences in relation to digital technology use: imaginative, epiphanic and symbiotic experiences. These experiences are the result of my reflective and intuitive analysis that have been corroborated by Sarah. She received a copy of the text below and confirmed that these three experiences reflect well her overall involvement with digital technology.

\subsection{Imaginative experience}

Sarah's appearance, attitude and utterance reveal a creative mind. This preliminary impression was soon substantiated by the description of her early beginnings in artistic expressions, just before leaving for Nowhere Island for the first time:

\footnotetext{
${ }^{3}$ The name of this island located in the South Pacific is fictitious too.
} 
I remember having this fantasy the night before I left. This fantasy was, I would be sitting at the bar in this, er, I visualised it, sitting at the bar in this hotel where I was working, and all these guests buying me drinks, which is really funny because I did not drink. But the main thing I would also be doing, they would be commissioning me to do paintings for them to take back from their holiday. And the thing was, it was such a vivid fantasy, I was in that job for only three months, but that is exactly what happened. I used to waitress during the day. I would be serving breakfast; then, I would go off and pencil in a sketch, then I would serve lunch. After lunch, I would pen it in and then the following day I would put in the wash, so I had this process and by the evening, I have sold it. I was selling these paintings [at] 50 [New Zealand] dollars. It was in 1977, 50 dollars, unframed, no mount or anything ... I was earning far more from my paintings than what I was from waitressing full time.

Many years later, when she worked as a receptionist at physiotherapy clinic, a wellknown New Zealand painter went to her place to collect a lumbar roll needed for his treatment. The paintings he saw hanging on her walls overwhelmed him, "Oh, my God! Who did those?" Upon Sarah's reply that she was the author of those paintings, he candidly rebutted, "You? ... I have known you all these years and thought you were a frivolous, empty-headed receptionist". Sarah giggled while sharing this experience. In addition to painting, Sarah also did sculpting; however, writing defines her imaginative experience. While Sarah acknowledges that her university studies equipped her well with writing skills, she hastily explains that these are subordinated to her creative spirit:

What I have always had was a really wonderful imagination, I have always been able to imagine things to the extent that I can feel and see and hear the characters in my head. I hear the dialogue ... In my mind it is almost like watching a film, and I hear the dialogues that I am writing down, what the characters are saying.

Sarah goes back in time and remembers her early writings of black comedy:

There was a phase in about 1984 when I wrote short stories. Just a few ... And I remember very nervously showing them to [my daughter's] father ... [who] was a poet, a pub poet ... His opinion meant a lot to me and I remember very nervously reading out one of my short stories. He sat there and went very quiet ... I said, 'Is it any good?' [laughs] Because I got the feeling that it was not any good, you know. He said, 'Well, actually it is good. In fact, it is very good ... I do not mind you painting, but I would rather you do not write anymore because I cannot handle competition'. That is what he said. Me being me I was a fool and I was mad in love with him I did not bother writing anymore. That is the only time I wrote short stories. However, it was not only love that stopped her from continuing writing; it was the clumsiness of handwriting. Sarah wrote these short stories by longhand and reasoned that making changes on her handwritten drafts encompassed an arduous endeavour. She was not able to type, a limitation that she wanted to overcome when she enrolled in a computer-training course at Waitopu Community Education Centre in 2002. Her first encounter with digital technology was tremendously frustrating:

I enrolled in this course, and the woman said, 'Can you type?' I said, 'No'. She said, 'Oh! I will get you on this'... And I swear! If I could have killed the woman at the end of the week, I would have done it, the woman on the computer screen. Because you get to, say, 99\%, if you got one wrong, you go back to square one again. It just drove me nuts! And everybody else in the course was off doing interesting things and I was stuck because I was the only one who could not type ... 'Oh, I cannot be bothered with this', and just quit ... And in the end ... it 
reinforced my fear of technology really [laughs]. 'Oh, I would not be any good at that'. 'Oh,

I am going to avoid it'. 'I can get by without it in my life'.

Sarah describes herself as a "technophobe": "[My daughter keeps telling me], 'You will never get it. Even if you spend a year, you still would not get it' ... She must be right [laughs]." Her daughter customises the setting options according to Sarah's preferences. Sarah admits that she cannot do it: "As I said, I am technophobic".

\subsection{Epiphanic experience}

After her first frustrating encounter, Sarah had to reconsider her averseness to digital technology as her daughter was growing up. She recalls her reflections of the consequences of not using technology: "There were teachers asking to email them assignments and I thought, 'Oh God, this is going to be a real problem for my daughter'". While this realisation urged Sarah to make a second attempt, it was a turn of fate something that she qualifies as a "happy accident" - that eventually brought digital technology closer to her. Sarah vividly remembers the morning of 26 August 2010:

It was one of those days, you know, when you look back to a key day, when everything kind of changes. That was the day I was in this particular [that] I only bought ... to do it up because I wanted another house, which was my original house ... I decided I wanted it back when [my daughter] was getting a bit older. And in order to get it back, I bought this other property to do it up, so I could have enough money to buy it back ... so I was happily doing up this other property. Then, there was a huge, torrential, downpour of rain the previous night. And there was a stream running through at the back of the property and the next morning I went to the end of my garden to look at the stream and it was not there. There was basically this massive landslip, a huge mudslide. 'Oh my God!' ... I remember walking back into the house thinking 'Stay calm, make a cup of tea' [laughs]. That is my answer to everything. And I made a cup of tea and could not deal with everything ... 'Can I ever be able to sell this property? Will I able to get my house back, the one that I owned?' [I] ... just wanted to escape and I just kind of opened the Waitopu News and there was an article about the Computers in Homes scheme and it mentioned there were only a couple of places left. And I thought, 'Oh, right, I'd better ring up', because it said that you get a free, er, a computer for 50 [New Zealand] dollars, if you do the course. So, I said, 'OK, well, I only have to stick to the course' ... I rang up, er, the Computers [in Homes] to get on the scheme ... And then, basically, I did something I have done since I was a little kid, I made stories in my head and I escaped into them.

Sarah recalls, "[The instructor] went back to basics for us... Even turning the computer on for me was, you know. It had to be basic". What she enjoyed the most was the entirely different approach the instructor took, compared to the course she failed to complete eight years earlier, in 2002.

The beauty of the course was that we barely had to do any typing [laughs]. That is why I was able to stick the course out because I knew I could not type. Oh God! I forgot the tutor's name now, but he was a lovely man and he sort of said, 'Look, you will be at different stages of how fast you can type ... I do not want the whole course governed by your different stages'. So he said, '... You just copy and paste the bits on, so you do not have to type the whole stuff ... Then, I teach you how you can manipulate and move things around'. The text was already there ... I barely had to type much at all. 
Twenty-six years after her false start in 1984, Sarah went back to writing her stories while doing the computer-training course in October 2010. However, she was still trying to write them by hand. Although she was not happy with the quality of her drafts, she had the determination to complete her writing:

I was to give up after the first chapter because it was, like, painful. It was an involved story, and I had already seen that I wanted to change things. But I was doing this course, I thought, 'Hey, if I type this on the computer, I could change this and switch paragraphs around so much easier'. So before the computer even arrived at home, I was already seeing the potential of the computer. Yeah, because I can remember the deputy principal of the high school coming round and saying, 'What do you think you will end up using your computer for?' I think I said, '[My daughter] will be doing school work and homework, but I have a book in my head that I want to get down'. I already knew then, while I was doing the course, that as soon as that computer arrived the first thing I would started doing was write the story down.

Eventually, Sarah learned how to type on a keyboard. She reasons, "Because I got the computer ... 'I'd better practice typing on it'. Because I was so slow, and thought, er, 'What should I write? I will write down the story that is in my head". Acquiring the ability to type only occurred after she discovered the editing functionalities of word processor software; the prospect of easily modifying text was an epiphany for Sarah:

Oh my God! This whole copy-and-paste thing, I realised that I could move things around so easily. When I had written those short stories [by hand because I was not able to type] in the early $80 \mathrm{~s}$, er, it is painful! I mean, if you wanted to change, move things around was a pain. It was like, er, I always painted and when you paint either it really goes well or starts going to custard and you try to retrieve the situation, usually it gets worse ... Whereas when I was writing on the computer, even if what I wrote was crap, I knew by the time I finished that day, by the time I changed things around and copied and pasted and deleted and everything and rewrote, it would be really good. So there will not be mistakes, in a sense. I could be totally relaxed and free to put anything I want down because I knew I could change it so easily with the click of a button. It gave me this freedom, I do not remember who said that, 'Creativity is allowing yourself to make mistakes; art is knowing which ones to keep'.

The discovery of using digital technology for writing the stories that Sarah always had in her head was a liberating experience. She confesses that the possibility of making mistakes has always caused anxiety on her:

So the computer gave me this means to be totally free to make mistakes, so I do. I always had this fear as a kid, I was always a nervous kid, I was terrified to make mistakes. My father used to come down on me so hard. I mean, I came home from school as a six years old and he would not allow me to go outside to play, unless I recited the tables and did it perfectly. And of course, I did not do it perfect ... So there is always that fear, the more nervous I got, the more anxious I got to do it right, the more is guaranteed I would do it wrong. Whereas with the computer, what I found is that it did not matter. I could do any mistakes I like because there is the delete button [laughs]. Nobody needs to know how many attempts I made to write something; they just see the end result, you know. And that is enormously liberating!

Sarah has nevertheless mixed feelings toward digital technology. She enjoys using a word processor, but her aversion to digital technology remains unchanged:

I find computers and technology, generally, very frustrating ... If I do not understand it and it does not do what I want it to do, I get really annoyed quite quickly. But with writing is the 
opposite; it makes life easier. It is not frustrating when I write; the computer tends to do what I want. It is funny because with other things, because I do not know anything about computers. Sarah conveys a sense of uncertainty and despair when using digital technology:

I look at [my daughter] on the computer and she has no fear whatsoever. She is quite confident. If she loses something, she can get it back. There is definitely more anxiety with me... I forgot to save just recently and suddenly the document disappeared, I do not know what I accidentally pressed. Then, I get anxious. 'Oh [expletive] that is my last hour's work! Where has it gone?' [My daughter] would come along and say 'Oh, it is alright. It is just here, yep. You just pressed this by accident'. Then, it comes, you know ... For me there is an element of anxiety because I do not understand it completely ... I would like to feel that I understand how it works, er ... It does not kind make a lot of sense [laughs]. The whole idea of different windows and all this, you know, how you can open so many up, it is like sci-fi to me.

Finally, the story that Sarah started handwriting in 2010 was completed using a word processor in late 2011. The original work was entirely rewritten; the main story was intertwined with other stories. The plot "changed dramatically" and one year later, the plot was modified again and put aside for two years. It was eventually published as a novel in June 2015. She praises digital technology for the flexibility it affords - e.g., "It was simply so much easier with the computer", "I can swap chapters around; it is so easy" - and sentences with a laugh, "I do not how people write novels by hand". In recognition of this achievement, she received a new laptop computer with the latest operating system in March 2016, which reminded her aversion to digital technology:

I hated the fact that when I got given the new laptop it was such a big adjustment as I had been used to working on the old [desktop computer] ... They gave me the laptop and I swear it sat there for about a month to six weeks... I knew I had to get used to working with a different word [processor] programme. At one point, I was doing emails on the new laptop but still wrote on the old one because it is the one that I was used to. I do not like change.

In the end, Sarah "packed up the old desktop, put it on the shed and stuck the laptop there and then I had no choice. I had to get used to it. Thank God I did - it is so much faster!" Her laptop is now her default technology.

\subsection{Symbiotic experience}

Sarah's creative mind and her ability to use a word processor constitute an inseparable unit in the writing endeavour. Sarah has a disciplined approach when it comes to writing. She does not like interruptions; she does not take phone calls and her daughter knows that she should not be around while Sarah is engrossed typing her stories. Even her fear of technology is temporarily suspended: "When I write I feel that the computer does what I want". She describes her state of immersion as a journey to another world: "I lose myself in [my writing]. Yeah. I lose myself in it. Even when I am buzzing, I am still wrapped up in the story. It takes me a while to get back to reality, I suppose".

Sarah sees the monotony of her job as a cleaner beneficial to her imaginative undertakings. The manual nature of the cleaning work she performs gives her the mental space to develop stories in her head. Furthermore, her imaginative mind manifested conspicuously during the long hours of conversations we had; they were interspersed with passages of these stories. However, these stories would never see the light of the 
day if it not were by digital technology. She grants it a prominent role in the materialisation of her imagination:

For me, the stories I write are that inner world. With the computer, once again, it was finding the tool to express the inner world ... So it is like I am just putting in what I already see, but just to allow others to see it. So when I write a story, it is often like a movie I watch and then, it is just putting it down, so other people can watch the movie ... The story was in my head, but I want to share it. I do not think people would have seen it without my computer. In expressing her inner world, Sarah takes advantage of some functionalities of word processor software. In her own account, she never "thought of writing [her stories] down" before discovering the editing functionalities available on a word processor. Moreover, she does not want to go back to hand writing anymore: "I find longhand writing so difficult now. I would say, I am so hooked into [digital technology] now". Sarah uses her latest work to exemplify her reliance on digital technology:

The children's book I am working on is so short, there are so few words, I mean, you are looking at about 400 words. They are not an issue to writing down on longhand anyway, although I have done it on the computer... If it breaks down, I would just replace it ... It is like going back ... It is just too painful ... I would not write novels without the computer.

Although Sarah admits that she does not utilise the advanced editing functionalities of word processor software (e.g., creation of sections, page numbering, track changes), she feels confident modifying text. She explains how seeing her stories written in front of her, as opposed to mental plots, helps her improve the structure and narrative:

When I talked to the editor the other day, I told him, 'Chapter 19 is too short; chapter 20 is too long'. So I took the beginning of chapter 20 and put it in chapter 19 ... And it is so much easier on the computer. It was not a biggie. In just a few seconds I altered that, completely altered the length of the chapter. I did not write anymore ... I do not necessarily see where the end of the chapter is when I am writing. I have a sense of it, but maybe not exactly ... Certainly, when I start writing a book, but the time I finish it, the start will change two or three times ... I do play around still a lot. It is afterwards that you can look back, almost outside yourself and say, 'Ah, this could be better here or that better there'. It is like my builtin editor. And that probably is the part that I really enjoy of the benefits of the computer.

The materialisation of her mental stories does not indicate the culmination of the imaginative process though. Sarah experiences the contradiction between her tendency of incessantly producing stories in her inner world and the prospect of having her stories truncated in a final document ready to be published. She describes this dilemma between her desire to keep her story evolving and releasing it:

The worst fear ... I certainly did not find it easy right at the end when the publishers or editors say, 'This is the final edit; this is it' ... I hated those emails because I still want to fiddle and change something ... Until it was actually in print, I wanted to keep it changing. Once it was in print, that was it. It is like it was done ... It is like giving birth and that is it. OK? Even if it is a deformity, you accept it. That is it ... Once it is in print, I have to let it go. Interestingly, digital technology represents more than just a convenient labour-saving tool to Sarah. She engages in online research to portray an accurate depiction of the background in which her stories are set up. Sarah describes herself as a perfectionist and wants to reflect this in her writing. She wants to make sure that the terms, historical details, temporal and geographical references are correct. Her meticulous style can be 
appreciated in her first published novel, which contains many references to Roman history in the first century of the Christian era. Sarah describes with detail certain aspects of the scenery, such as sunrise and sunset times as well as tide levels. Online searches furnish her with all these details. Sarah summarises the symbiotic interaction between her creative mind and digital technology with the following statement: "It is where the computer works perfectly with my imagination ... it is a sort of collaboration".

\section{Discussion and Conclusion}

This phenomenological study reveals the lived experience of Sarah, a self-confessed technophobe, who has been able to write a novel using word processor software and get it published. Attributing her achievements as a writer solely to digital technology likens to assuming a technological deterministic position, which I reject. Her ability of using digital technology did not make Sarah a writer. However, digital technology especially word processor software - became a catalyst that allowed Sarah to materialise her talent as a storyteller. She is a creative person that has established a disciplined routine for writing stories in which word processor software plays a crucial role. The essence of the phenomenon under study is constituted by three interdependent experiences. First, the imaginative experience, which reveals her creative character that is incessantly visualising fantastic stories. Second, the epiphanic experience as the moment of discovery, when Sarah realised that word processor software constitutes the platform for her imagination coming into being. Third, the symbiotic experience that represents how ingrained digital technology has become in her writing; not only to produce the text of her novels but also as a source of information for giving her stories factual accuracy. However, there is an element that still lies underneath these three experiences, the anxiety that using digital technology produces on her.

Although this phenomenological study relies on the experience of one participant only, it offers two contributions. The first one is a demonstration of the repercussions digital technology can have on people's lives. Sarah has reasons to believe now that she is in the path of leaving her job as a cleaner to become a novelist. Sarah intimates, "When I have another couple of books out there, I would probably think of myself as a writer". After a pause, she assertively reflects, "I would like to end up thinking of myself as a writer". At the time of writing this paper, Sarah's second novel had already been completed. In addition, Sarah is working simultaneously on a new novel and a children's book. In this sense, her experience is an instantiation of how individuals derive value from using digital technology as a sense of personal achievement that transcends purely monetary considerations - cf. Sen's capability approach [28]. Sarah shares her intention to continue writing after retirement simply "because it is fun". The second contribution of this study lies on the insights transcendental phenomenology reveals. By adopting transcendental phenomenology as a method of inquiry, I do not aim at making this study replicable; even less, making my findings predictable. What this study offers instead is a thick description that reveals the essence of the phenomenon of engaging with digital technology as lived by Sarah, a self-confessed technophobe. The analysis reveals Sarah's intentions and consciousness in her use of word processor 
software. Given that at its fundamental level, information systems research is about understanding the interplay between individuals and digital technology, phenomenology as a method affords scrutinising the process of how "data becomes information in the consciousness of a human subject" [12, p. 200]. Researchers interested in understanding how individuals exercise judgment and construct meaning in their engagement with digital technology can adopt a transcendental phenomenological approach.

The findings of this research signal a promising research direction. The discovery of the symbiotic experience opens opportunities for further studying contemporary phenomena characterised by the intimate relationship with digital technology in multiple spheres of personal life, such as health and sports, human interaction and entertainment.

Acknowledgement. 2020 Trust made possible the fieldwork of this study.

\section{References}

1. Braa, J, Hanseth O, Heywood A, Mohammed W, Shaw V (2007) Developing health information systems in developing countries: The flexible standards strategy. MIS Quarterly 31: 381-402.

2. Jha, SK, Pinsonneault A, Dubé L (2016) The evolution of an ICT platformenabled ecosystem for poverty alleviation: The case of eKutir. MIS Quarterly 40: 431-445.

3. Puri, SK (2007) Integrating scientific with indigenous knowledge: Constructing knowledge alliances for land management in India. MIS Quarterly 31: 355-379.

4. Silva, L (2007) Institutionalization does not occur by decree: Institutional obstacles in implementing a land administration system in a developing country. Information Technology for Development 13: 27-48.

5. Suchman, LA (2007) Human-machine reconfigurations: Plans and situated actions. 2nd ed., Cambridge University Press, New York

6. Faraj, S, Azad B (2012) The materiality of technology: An affordance perspective. In: Leonardi PM, Nardi BA, Kallinikos J (eds) Materiality and organizing: Social interaction in a technological world, Oxford University Press: Oxford. pp 237-258.

7. Robey, D, Raymond B, Anderson C (2012) Theorizing information technology as a material artifact in information systems research. In: Leonardi PM, Nardi BA, Kallinikos J (eds) Materiality and organizing: Social interaction in a technological world, Oxford University Press: Oxford. pp 217236.

8. Introna, L (2013) Epilogue: Performativity and the becoming of sociomaterial assemblages. In: de Vaujany F-X, Mitev N (eds) Materiality and space: Organizations, artefacts and practices, Palgrave Macmillan: Basingstoke.

9. Orlikowski, WJ (2000) Using technology and constituting structures: A practice lens for studying technology in organizations. Organization Science 11: 404-428. 
10. Kallinikos, J, Aaltonen A, Marton A (2013) The ambivalent ontology of digital artifacts. MIS Quarterly 37: 357-370.

11. Ciborra, C (2004) Encountering information systems as a phenomenon. In: Avgerou C, Ciborra C, Land F (eds) The social study of information and communication technology: Innovation, actors, and contexts, Oxford University Press: Oxford. pp 17-37.

12. Boland Jr, RJ (1985) Phenomenology: A preferred approach to research in information systems. In: Mumford E, Hirscheim RA, Fitzgerald G, WoodHarper AT (eds) Research methods in information systems. pp 193-201.

13. Weil, MM, Rosen LD, Wugalter SE (1990) The etiology of computerphobia. Computers in Human Behavior 6: 361-379.

14. Bandura, A (1982) Self-efficacy mechanism in human agency. American Psychologist 37: 122-147.

15. Meier, ST (1985) Computer aversion. Computers in Human Behavior 1: 171179.

16. Rosen, LD, Weil MM (1995) Computer availability, computer experience and technophobia among public school teachers. Computers in Human Behavior 11: 9-31.

17. Beckers, JJ, Schmidt HG (2003) Computer experience and computer anxiety. Computers in Human Behavior 19: 785-797.

18. Brosnan, MJ (1999) Modeling technophobia: A case for word processing. Computers in Human Behavior 15: 105-121.

19. Introna, L, Whittaker L (2003) The phenomenology of information systems evaluation: Overcoming the subject/object dualism. In: Wynn EH, Whitley EA, Myers MD, DeGross JI (eds) Global and organizational discourse about information technology, Springer US: New York. pp 155-175.

20. Küpers, WM (2009) The status and relevance of phenomenology for integral research: Or why phenomenology is more and different than an "Upper Left" or "Zone \#1" affair. Integral Review 5: 51-95.

21. Jopling, DA (1996) Sub-phenomenology. Human Studies 19: 153-173.

22. Küpers, WM (2015) Phenomenology of the embodied organization: The contribution of Merleau-Ponty for organizational studies and practice. Palgrave Macmillan, Basingstoke

23. Moustakas, C (1994) Phenomenological research methods. Sage, Thousand Oaks

24. Jennings, JL (1986) Husserl revisited: The forgotten distinction between distinction and phenomenology. American Psychologist 41: 1231-1240.

25. Lopez, KA, Willis DG (2004) Descriptive versus interpretive phenomenology: Their contributions to nursing knowledge. Qualitative Health Research 14: 726-735.

26. Creswell, JW (2009) Research design: Qualitative, quantitative, and mixed methods approaches. 3rd ed., Sage, Los Angeles

27. Merleau-Ponty, M (2014) Phenomenology of perception [1974]. Routledge, London

28. Sen, AK (1999) Development as freedom. Alfred A. Knopf, New York 